\title{
SHIPBORNE AND GROUND-BASED LIDAR MONITORING OF THE ATMOSPHERE OVER THE LAKE BAIKAL IN 2018
}

\author{
Yurii S. Balin ${ }^{1}$, Marina G. Klemasheva ${ }^{1}$, Grigorii P. Kokhanenko ${ }^{1}$, Sergey V. Nasonov ${ }^{1 *}$, Ioganes E. \\ Penner $^{1}$ \\ *Email:nsvtsk@gmail.com \\ ${ }^{1}$ V.E. Zuev Institute of Atmospheric Optics, Rus. Acad. Sci., Tomsk 634021, Russia
}

\begin{abstract}
The paper presents the results of studies aimed at the analysis and assessment of atmospheric pollution over the Lake Baikal in the summer. This information is necessary to create physical models of the formation and transfer of atmospheric aerosol fields, taking into account the physical and geographical features of the Baikal region. Measurements were carried out by a lidar «LOSA-A2» installed on the scientific-research vessel «Academician V.A. Koptyug». The vessel's route passed along the South, Middle and Northern Baikal, from July 15, 2018 to July 26, 2018. At the same time, observations were conducted using lidar «LOSA-M2». It was located in the background area at Boyarsky stationary site $\left(51.84^{\circ} \mathrm{N}, 106.06^{\circ} \mathrm{E}\right)$, in the south-eastern part of the lake. The results of changes in the spatial structure of atmospheric aerosol fields in background conditions and during forest fires are shown.
\end{abstract}

\section{INTRODUCTION AND METHODOLOGY}

Interest in the Lake Baikal is associated with high requirements for the protection of nature of this unique object and the features of natural conditions [1-4]. Here, the formation and distribution of atmospheric admixtures in the summer period is influenced by mountain terrain and significant temperature contrasts between the cold surface of the lake and the atmosphere.

One of the most significant sources of pollution of the atmosphere of the Baikal region is smoke aerosol from forest fires, the number of which is increasing due to climate warming in the region.

The sounding of aerosol fields was carried out using the mobile aerosol-Raman lidar «LOSAA2». It was for the first time tested in 2018 in this expedition. Lidar was located on the lower deck aft of the vessel. Thanks to this, it was possible to direct it vertically upwards or to tilt it over the horizon. The appearance of the «LOSA-A2» lidar is shown in Fig. 1a.

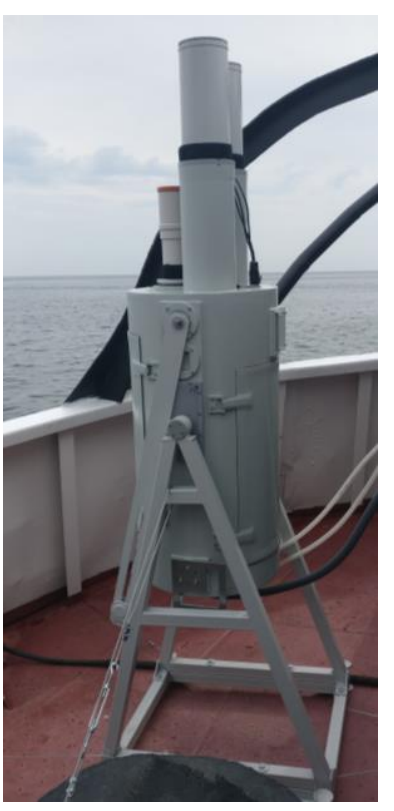

(a)

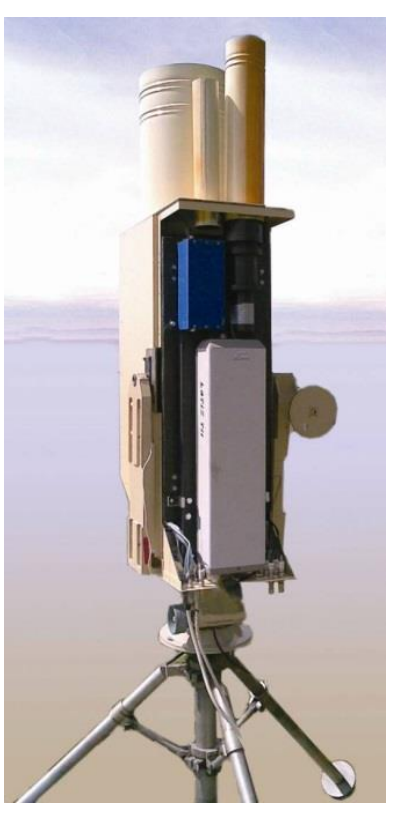

(b)
Fig.1 Appearance of mobile aerosol-Raman lidars «LOSA-A2» (a) and «LOSA-M2» (b)

The lidar case is made of carbon fiber, which increases the stability of the disposition of optical elements under mechanical loads during transportation and operation of the lidar. In addition, the case has a low dependence from temperature.

The lidar uses as the transmitter LS-2131M laser (LOTIS TII, Belarus) operating at two wavelengths $1064 \mathrm{~nm}$ and $532 \mathrm{~nm}$ with a frequency of $20 \mathrm{~Hz}$. The radiation passes a collimator, reducing the beam divergence angle to $0.5 \mathrm{mrad}$. A phase polarization plate is inserted between the laser and the collimator, which 
changes the plane of linear polarization or creates circular polarization.

The lidar receiving part is made in the form of two identical lens objectives with a diameter of 110 $\mathrm{mm}$ and located symmetrically relative to the optical axis of the transmitter. One of these objectives is designed to register lidar signals in the visible range wavelengths (signals of elastic and Raman scattering - $532 \mathrm{~nm}$ and $607 \mathrm{~nm}$, orthogonal polarization components at a wavelength of $532 \mathrm{~nm}$ ). This receiving channel uses photomultipliers H11526-20-NF («HamamatsuPhotonics», Japan), operating in analog mode. The signal of Raman scattering on atmospheric nitrogen molecules is registered by the photodetector module H11706P-40-MOD («HamamatsuPhotonics», Japan) operating in the photon counting mode. The second receiving objective is designed to receive backscattered radiation at a wavelength of $1064 \mathrm{~nm}$, using the developed original photodetector module based on the C30956E-EU avalanche photodiode («PerkinElemer», USA), operating in analog mode.

The probing of aerosol fields at the Boyarsky stationary site is carried out by the multifrequency mobile aerosol-Raman lidar «LOSAM2» (Fig. 1b) at two laser wavelengths of 1064 $\mathrm{nm}$ and $532 \mathrm{~nm}$ [5]. The detection of elastic backscattered radiation at these wavelengths was carried out in the analog mode, and for $532 \mathrm{~nm}$ also in the photon counting mode. In addition, a signal is detected at an offset wavelength of 607 $\mathrm{nm}$ of spontaneous Raman scattering in the photon counting mode.

The general preliminary interpretation of the data of sounding was performed on the basis of the analysis of the vertical cross-sections of the aerosol field of the troposphere represented in the units of the scattering ratio $R$ $\left(\lambda_{1}, \mathrm{z}\right)=\left(\beta^{\mathrm{a}}\left(\lambda_{1}, \mathrm{z}\right)+\beta^{\mathrm{m}}\left(\lambda_{1}, \mathrm{z}\right)\right) / \beta^{\mathrm{m}}\left(\lambda_{1}, \mathrm{z}\right)$, where $\beta^{\mathrm{a}}\left(\lambda_{1}, \mathrm{z}\right)$ and $\beta^{\mathrm{m}}\left(\lambda_{1}, \mathrm{z}\right)$ are the aerosol and molecular backscattering coefficients at the wavelength of $\lambda_{1}=1064 \mathrm{~nm}$.

The main attention of the researches was focused on the study of the temporary changes in the vertical structure of aerosol fields and the identification of the physical mechanisms of their formation.

\section{ANALYSIS OF LIDAR DATA}

During the passage of the vessel along the Middle Baikal on July 19, 2018, the atmosphere was cleared by rains the previous night, the lidar recorded background concentrations of aerosol. An example of such results is shown in Fig. 2a, where you can see small values of the atmospheric scattering ratio parameter.

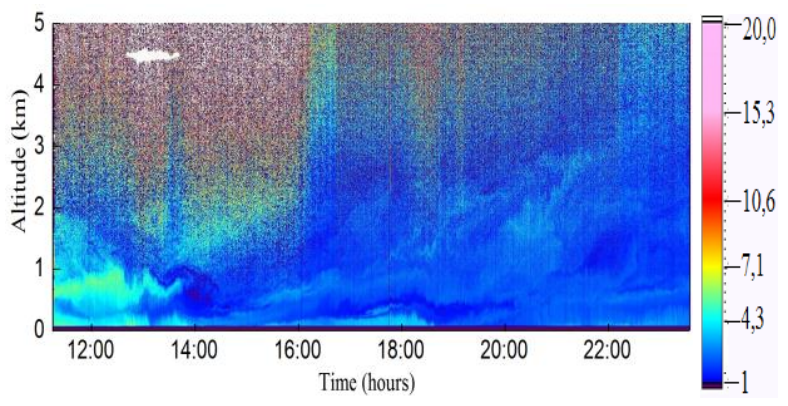

(a)

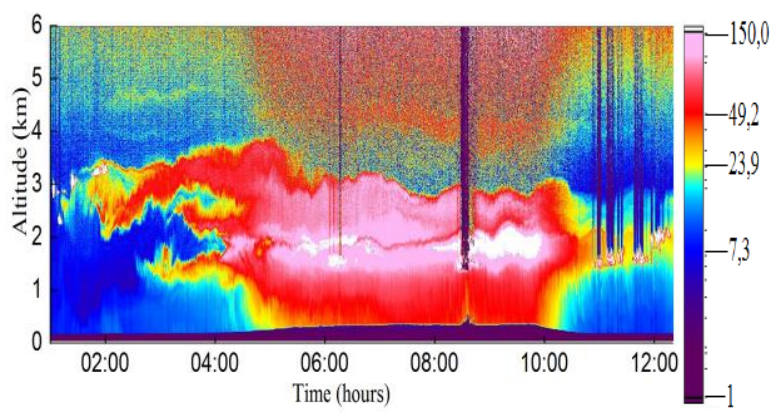

(b)

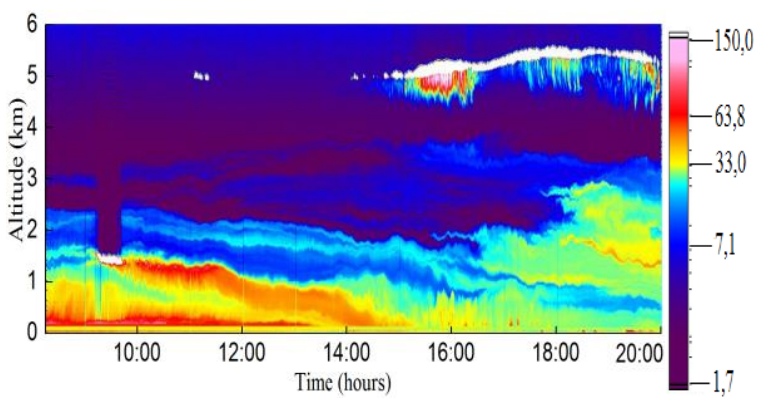

(c)

Fig.2 Spatiotemporal structure of aerosol field, obtained: (a) - by the lidar at the research vessel «Academician V.A. Koptyug» on July 19, 2018; (b) - by the lidar at the research vessel «Academician V.A. Koptyug» on July 22, 2018; (c) - by the lidar at the Boyarsky stationary site on July 22, 2018. Color scale is given in scattering ratio units. 
According to laser-sensing data, the first traces of a smoke train from forest fires from the Krasnoyarsk Territory and Yakutia (Fig. 2b) were observed while the vessel was near Severobaykalsk. They appeared after midnight and were observed as independent aerosol formations with a thickness of 200-300 m (Fig. $2 b)$. Further, there is an expansion of the smoke train in the altitude range of $2-3 \mathrm{~km}$, up to a height of 3.5-4 km in the morning (04:00 - 05:00 a.m.). The aerosol content in the atmosphere exceeds the background values dozens of times. In the same time period, with a delay of about 1.5 hours (02:30 a.m.), the presence of a lower second smoke train at an altitude of $1.5 \mathrm{~km}$ was detected. This is probably due to the orographic features of the surrounding mountain terrain. These two smoke trains expanded during the observation time and merged into a single one at an altitude of about $2 \mathrm{~km}$ (04:20 a.m.). After that, within an hour there is a sharp filling of the lower layers of the atmosphere with a smoke aerosol, right up to the surface layer. Both smoke trains, joined to the total mass, have a pronounced border between them in the region of $2 \mathrm{~km}$. This indicates a different concentration of aerosol at the boundaries of these smoke trains.

At 11:55 a.m. local time the vessel moved away from Severobaikalsk towards the eastern shore of the. The presence of smoke aerosol in the atmosphere, but of a lower concentration, was recorded according to laser sensing data along the route.

The increased aerosol content in the same period (July 22) was also recorded during observations at the Boyarsky stationary site (South Baikal). Here, measurements were carried out using a «LOSAM2» lidar [5], in parallel with ship observations. On this day in the stationary site for weather conditions, the experiment began at 8:15 a.m. At this time, at an altitude of $250 \mathrm{~m}$ and $1500 \mathrm{~m}$, layers with a high content of aerosol were observed (Fig. 2c). In the afternoon, the upper layer began to descend, while the lower layer weakened in aerosol concentration, and by $3 \mathrm{pm}$ both layers lowered, and clouds appeared in the atmosphere for $5 \mathrm{~km}$. According to the data of the meteorological complex on the Boyarsky stationary site, the experiment on July 22, 2018 took place under conditions of a decrease in atmospheric pressure (from $740 \mathrm{~mm} \mathrm{Hg}$ to 713 $\mathrm{mm} \mathrm{Hg}$ ) and relative humidity (from $60 \%$ to $30 \%$ ), with mostly northwesterly wind direction.

Similar data of lidar observations once again prove the complex processes of formation of the structure of aerosol fields above the lake.

Similar lidar studies of the formation of the structure of aerosol fields in mountain conditions over the Lake Baikal were made earlier [6]. In this work, ship studies were carried out of the specific features of the formation of longitudinal and transversal aerosol lidar transect depending on the lay of land (areas of South and Middle Baikal). Correlation analysis of the altitude distribution of the optical thickness and the altitude distribution of the mountain profile along the route of the vessel showed that the greatest correlation is observed in the lower layer of the atmosphere 0.5 $1.5 \mathrm{~km}[6]$.

\section{SUMMARY}

The analysis of the spatial-temporal distribution of the aerosol in atmosphere over the Lake Baikal according to the results of ship measurements in July 2018 was conduct. Synoptic conditions and orographic features of the coastal zone of the Lake Baikal had a significant impact on the distribution of aerosol over the lake.

In this paper, we present the results of time dynamics of the formation of complex structures altitude airborne admixtures from forest fires in the coastal zone, which is due to features of airflow over mountain terrain.

\section{ACKNOWLEDGEMENT}

The authors thank the head of the Laboratory of Hydrochemistry and Atmosphere Chemistry Limnological Institute SB RAS Khodzher T.V. for organization the expedition «Baikal-18».

This work was supported by Russian Science Foundation grant № 18-77-10035.

\section{REFERENCES}

[1] Pancheko M. V., Domysheva V. M., Pestunov D. A., Shmargunov V. P. Spatial distribution of the carbon-containing gas fluxes direction in the "water - atmosphere" system in the littoral zone of Lake Baikal in summer // International Journal of 
Hydrology Vol. 2, Issue 2 - 2018. P 195-196. DOI: 10.15406/ijh.2018.02.00068.

[2] Obolkin V., Khodzher T., Sorokovikova L., Tomberg I. Effect of long-range transport of sulphur and nitrogen oxides from large coal power plants on acidification of river waters in the Baikal region, East Siberia // International Journal of Environmental Studies. 2016. 73(3): P. 452461.

[3] Arshinov M. Yu., Belan B. D., Ivlev G. A., Rasskazchikova T. M. Spatiotemporal characteristics of air circulation in the hollow of Lake Baikal // Atmospheric and oceanic optics, V. 14, No. 04, P. 263-266, (2001).

[4] Balin Yu. S., Klemasheva M. G., Kokhanenko G. P., Nasonov S. V., Novoselov M. M., Penner I. E. Vertical structure of the aerosol fields of the atmosphere in the period of forest fires over Lake Baikal in 2015 // Proc. SPIE 10035, 22nd International Symposium on Atmospheric and Ocean Optics: Atmospheric Physics, 100354D (29 November 2016) doi: 10.1117/12.2249294.

[5] Balin Yu. S., Bairashin G. S., Kokhanenko G. P., Klemasheva M. G., Penner I. E., and Samoilova S. V. "LOSA-M2" aerosol Raman lidar // Quantum Electron. 41 (10), 945-949 (2011).

doi:

10.1070/QE2011v041n10ABEH014574.

[6] Balin, Y., Ershov, A., Penner, I. Shipborne LIDAR Investigations of Aerosol Fields in the Atmosphere Over Lake Baikal // 22nd Internation Laser Radar Conference (ILRC 2004), Proceedings of the Conference held 12-16 July, 2004 in Matera, Italy. Edited by Gelsomina Pappalardo and Aldo Amodeo. ESA SP-561. Paris: European Space Agency, 2004, P.665-668. 